\title{
JUSTIFICATION OF CONSTRUCTIVE AND TECHNOLOGICAL PARAMETERS OF VIBRATING SEEDING UNIT
}

\author{
Alexander Machkarin, Andrey Ryzhkov, Oleg Chehunov, Alexey Makarenko \\ Belgorod State Agricultural University named after V. Gorin, Russia \\ machkarin@mail.ru ,ryzhkovbgsha@yandex.ru,olegbelgorod@mail.ru,makarbelg@mail.ru
}

\begin{abstract}
The expediency of using a direct sowing seeder SDM-6x2 with a vibrating sowing device for sowing winter wheat has been substantiated. The structural diagram of a seeder with a vibrating sowing device is presented. The theoretical foundations of the operation of the vibratory sowing apparatus are stated and the regularities of the process of dosing seeds during sowing are theoretically investigated, which makes it possible to substantiate its design and technological parameters. On the basis of a theoretical analysis of the working process of sowing winter wheat seeds using a vibrating sowing apparatus, analytical dependences of the actual and calculated specific weight costs on the acceleration of vertical and horizontal oscillations of the apparatus trough were obtained, which graphically illustrated the uniformity of the distribution of winter wheat seeds. In the research of the working process of dosing winter wheat seeds with a vibration sowing device, the following were obtained: an analytical expression for determining the value of unevenness and instability of seeding, the influence of the amplitude and frequency of oscillations on the speed of seed movement, taking into account the design and technological parameters of the vibration sowing device. In the research of the working capacity of the vibratory sowing device, the theoretical premises were checked, and the optimal design and technological parameters were substantiated. On the basis of the studies carried out, the possibility of using a vibrating sowing device of the proposed design for sowing winter wheat seeds with an uneven dosage that is within acceptable agrotechnical limits has been experimentally confirmed. As a result of using a vibrating sowing device, the uniformity of seed distribution in the soil is increased.
\end{abstract}

Keywords: sowing, wheat, uniformity, vibration, apparatus.

\section{Introduction}

One of the directions of improving seeding machines, including ordinary grain seeders, is the development of working bodies that ensure uniform distribution of seeds in the grooves along the seeder and along the depth of their incorporation with soil. The fulfillment of the first condition largely depends on the seeding device as a technical means for selecting, metering and supplying seeds to the closing working bodies of the seeder-openers. One of the options for solving this problem is the use of vibration seeding devices in the technological process of the seeder operation [1;2]. The purpose of the work is to increase the efficiency of growing grain by optimizing the design and technological parameters of the vibratory seeding machine of the seeder. The object of the research is the working process of sowing winter wheat seeds with a seeder with a vibrating sowing device. The subject of the research is the regularities of the uniform distribution of seeds in the soil during the operation of a seeder with a vibrating sowing device.

\section{Materials and methods}

On domestic seed drills, the most widespread is the reel sowing device, and recently it has been supplemented with an apparatus for centrifugal dosing of seeds and pneumatic transporting of them to the closing working bodies, providing a strip method of sowing [3;4].

A serious drawback of the reel sowing device is the formation of an impulsive seed flow. Such a device works unsatisfactorily when sowing small-seeded crops with a low rate of their consumption per hectare. All of the above devices are complex both structurally and technologically, which significantly increases the cost of seeders in general. In addition, most drills with these machines are single-row and not suitable for different method of sowing. The working process of a vibratory sowing device (RU 2300183) is based on the property of a bulk material in a state of vibration to behave like a viscous liquid, which ensures a uniform multi-jet flow of seeds [5].

The use of a vibrating sowing device on the SDM 6x2 disc mulching seeder will improve the uniformity of seeding and distribution of seeds in the soil.

At the Belgorod plant "Belagromash-service", a prototype disc mulching seeder with a vibrating sowing device was manufactured (Fig. 1). 


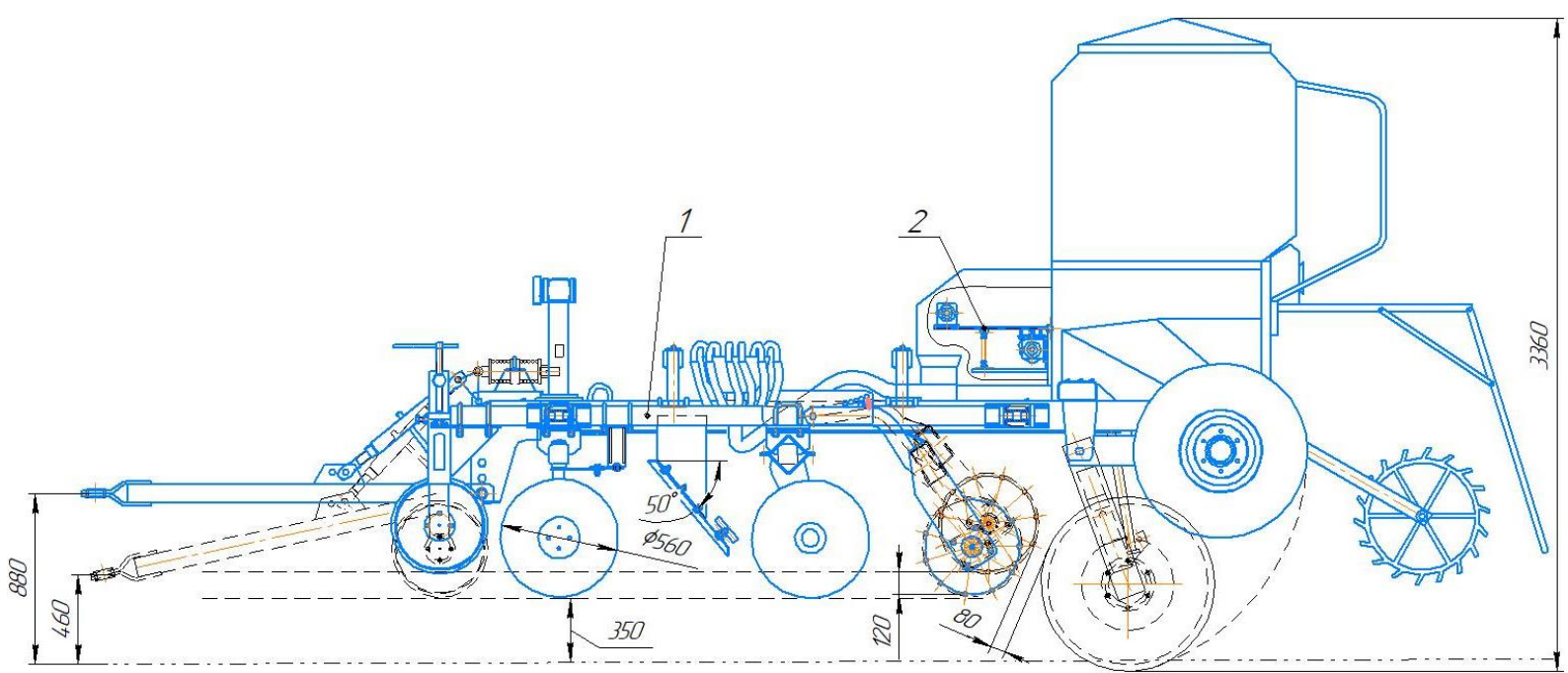

Fig. 1. Disc mulching seeder with vibrating sowing device:

1 - seeder SDM 6x2;2 - vibrating sowing device

Unevenness and instability of sowing seeds in twenty four-row seeders is determined for half of the working width; for machines with more than 24 seeding devices (seed tubes), the above indicators are determined for at least 12 seeding devices (seed tubes).

After installing the seeder at the specified seeding rate, samples are taken with a repetition of at least three times. The seeds sown by each sowing device (seed tube) are collected in containers and their weight or quantity is determined. To determine the unevenness and instability of sowing non-flowing seeds of herbs or fertilizers, at least three samples are taken for each of three volume fillings: with full, $1 / 2$ and $1 / 8$ of the volume of the seed or fertilizer box (hopper). The indicators are determined in natural field conditions or on a special stand simulating the operation of the unit in field conditions by vibration.

Additional mixing of seeds or fertilizers in the bunker during sampling is not allowed.

We find the average weight consumption of winter wheat seeds [6]:

$$
W=\frac{2 r l \gamma}{T} \sqrt{\frac{r g}{b}} \int_{t_{1}}^{t_{2}} \sqrt{1-\lambda \cos \omega t} d t,
$$

where $r$-radius of the outlet, $\mathrm{mm}$;

$l$ - tray length, $\mathrm{mm}$;

$b$ - tray width, mm;

$\gamma$ - specific weight of seeds, $\mathrm{g} \cdot \mathrm{m}^{-2} \cdot \mathrm{s}^{-2}$

$T$ - oscillation period, s;

$g$ - acceleration of gravity, $\mathrm{m} \cdot \mathrm{s}^{-2}$;

$\lambda$ - coefficient characterizing the vibration mode.

From formula (1) it can be seen that the average weight consumption depends on the parameters and vibration mode, as well as on the physical and mechanical properties of the grain.

Formula (1) does not reflect the dependence of the flow rate on the ratio of the hole size and grain particles. To check and clarify the obtained dependences, experiments were carried out on an installation with an oscillating chute.

Based on the experimental studies, the following dependencies were obtained for the outflow of winter wheat seeds $(\lambda=0.5 \ldots 0.85$ - coefficient characterizing the vibration mode $)$ with vertical oscillations:

$$
\alpha_{H . v}=-8.713+2.149 j
$$

and horizontal ones

$$
\alpha_{H . h}=11.76-0.4716 j
$$

where $j$-acceleration of the chute vibrations, $\mathrm{mm}^{-2} \cdot \mathrm{s}^{-2}$. 
The dependence of the average flow rate and angles $\alpha_{\mathrm{H}}$ on vibration acceleration, outlet size and grain moisture were studied. When processing the results of the experiments, dimensionless quantities were used.

$$
G=\frac{W_{f}}{W} \text { and } X=\frac{D}{d}
$$

where $\quad W_{f}$ and $W-$ actual and estimated costs;

$D$ - diameter of the outlet;

$d$ - average particle diameter of grain, at that:

$$
G=\frac{X}{A X+B},
$$

where $A$ and $B$ - coefficients whose values for sized seeds were found using the method of least squares.

For example, for wheat grain, formula (3) will take the form:

- in case of vertical vibrations

$$
W_{V}=\frac{2 \gamma d r \sqrt{\frac{r g}{b} u}}{0.2655+30.37 \frac{d}{D}},
$$

- and horizontal

$$
W_{V}=\frac{2 \gamma r \sqrt{\frac{r g}{b} u}}{0.3054+28.54 \frac{d}{D}} .
$$

a)

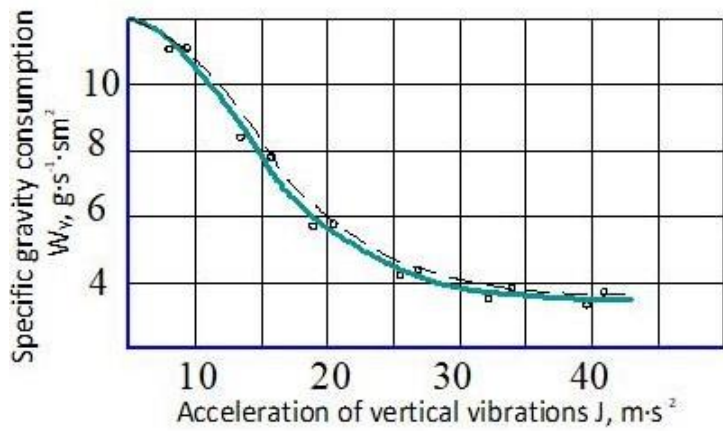

b)

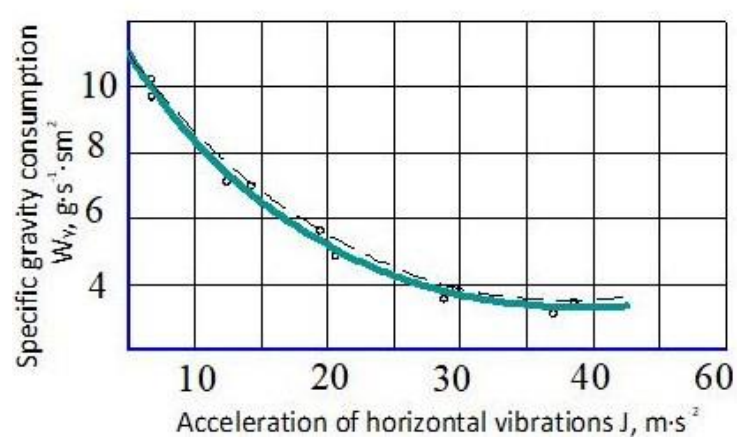

Fig. 2. Dependence of the actual (solid lines) and calculated (dashed lines) specific weight flow rates $W y$ on the acceleration of vertical (a) and horizontal (b) vibrations of the trough

The dependences obtained analytically are confirmed by the results of an experimental study of the influence of vibration modes on the weight consumption of seeds.

Some deviations in the calculated and experimental data are explained by the different density of the sowing seeds.

The degree of vibration impact on seed dosage is conveniently estimated by the value of the angle $\alpha_{H}$, which can be measured from the self-braking condition.

$$
\alpha_{H}=90^{\circ}-(\beta+2 \psi)
$$

where $\psi$-angle of internal friction;

$\beta$ - pressure angle of a particle of the upper layer on a particle of the lower layer, it was established empirically, and all the seeds have the same value. 
Since the angle $\alpha_{H}$ increases with increasing vibration acceleration, equality (5) is valid only with a simultaneous decrease in the angle of internal friction. From expression (5) we can find the effective value of the internal angle of friction.

$$
\psi=\frac{90^{\circ}-\left(\alpha_{H}+\beta\right)}{2}
$$

The process of grain outflow is characterized by a sharp decrease in internal forces, due to which grain flowability remains constant, which makes sowing more uniform.

The degree of vibration impact depends on the physical and mechanical properties of the seeds. In order to achieve a stable outflow of the latter, the chute should be given large accelerations. The flow process is also influenced by the direction of the oscillations.

The effective value of the angle of internal friction as the vibration acceleration increases with vertical vibrations decreases faster than with horizontal ones (Table 1).

Effective value of the angle of internal friction

\begin{tabular}{|c|c|c|c|c|}
\hline \multirow{2}{*}{ Vibration acceleration, $\mathbf{m} \cdot \mathbf{s}^{-2}$} & \multicolumn{2}{|c|}{$\boldsymbol{\delta}=\mathbf{0}$} & \multicolumn{2}{c|}{$\boldsymbol{\delta}=\mathbf{9 0}$} \\
\cline { 2 - 5 } & $\alpha_{H}$ & $\psi$ & $\alpha_{H}$ & $\psi$ \\
\hline 0 & $90^{\circ}$ & $90^{\circ}$ & $9^{\circ}$ & $34^{\circ}$ \\
\hline 10 & $16^{\circ} 30^{\prime}$ & $30^{\circ} 15^{\prime}$ & $12^{\circ} 50^{\prime}$ & $32^{\circ} 05^{\prime}$ \\
\hline 20 & $21^{\circ} 10^{\prime}$ & $27^{\circ} 55^{\prime}$ & $34^{\circ} 20^{\prime}$ & $12^{\circ} 20^{\prime}$ \\
\hline 30 & $25^{\circ} 50^{\prime}$ & $25^{\circ} 55^{\prime}$ & $55^{\circ} 50^{\prime}$ & $11^{\circ}$ \\
\hline 45 & $33^{\circ}$ & $22^{\circ}$ & $90^{\circ}$ & 0 \\
\hline 60 & $40^{\circ}$ & $18^{\circ} 30^{\prime}$ & $90^{\circ}$ & 0 \\
\hline 80 & $50^{\circ}$ & $13^{\circ} 30^{\prime}$ & $90^{\circ}$ & 0 \\
\hline
\end{tabular}

A certain angle of friction $\alpha_{H}$ corresponds to a stable outflow of various seeds. For winter wheat seeds, it corresponds to $28^{\circ}-30^{\circ}$. At the same time, its effective value calculated by formula (6) is in the range of $23^{\circ}-28^{\circ}$.

The study of the working process of a seeder with the proposed vibratory sowing device was carried out on the following backgrounds:

- sowing grain on buckwheat stubble;

- sowing grain on stubble of large-stalk crops (maize).

The optimization criterion was the uneven seeding $\delta_{\theta}$. This criterion is influenced by the following factors: vibration frequency $\left(x_{1}\right)$, vibration amplitude $\left(x_{2}\right)$, trough angle to the horizon $\left(x_{3}\right)$, brush angular velocity $\left(x_{4}\right)$, seeder speed $\left(x_{5}\right)$, brush diameter $\left(x_{6}\right)$, width chute $\left(x_{7}\right)$, gap between the brush and chute $\left(x_{8}\right)$. The search for the optimal combination of factors that affect the seeding process with a vibration apparatus was carried out according to the method of planning a multifactorial experiment.

The values of the coefficients of the regression equation were obtained using a computer program "Eureka: The Solver, Version 1.0".

After comparing the absolute values of the regression coefficients and the absolute value of their confidence interval, we obtained the following regression equation:

$$
\begin{aligned}
& \delta=0.98+0.92 \cdot x_{2}+0.55 \cdot x_{4}+0.90 \cdot x_{5}+0.97 \cdot x_{7}+1.07 \cdot x_{8}+1.01 \cdot x_{1} x_{2}+0.56 \cdot x_{1} x_{4}+ \\
& +0.96 \cdot x_{1} x_{5}+0.93 \cdot x_{2} x_{3}+1.06 \cdot x_{2} x_{4}+1.02 \cdot x_{2} x_{5}+0.72 \cdot x_{3} x_{5}+1.01 \cdot x_{4} x_{5}+0.85 \cdot x_{1} x_{2} x_{3}+ \\
& +0.94 \cdot x_{1} x_{2} x_{4}+1.06 \cdot x_{1} x_{2} x_{5}+0.81 \cdot x_{1} x_{3} x_{5}+0.84 \cdot x_{1} x_{4} x_{5}+1.01 \cdot x_{2} x_{3} x_{4}+1.00 \cdot x_{2} x_{3} x_{5}+ \\
& +1.09 \cdot x_{2} x_{4} x_{5}+0.42 \cdot x_{1} x_{2} x_{3} x_{4}+0.98 \cdot x_{2} x_{3} x_{4} x_{5}+0.68 \cdot x_{1} x_{2} x_{3} x_{4} x_{5}
\end{aligned}
$$

As a result of the obtained equation, we can conclude that the irregularity of seeding $\delta$ is significantly influenced by: the amplitude of oscillations $\mathrm{x}_{2}$, the angular speed of the brush $x_{4}$, the speed of the seeder $x_{5}$, the width of the chute $x_{7}$, the gap between the brush and the chute $x_{8}$, as well as the interaction of the factors $x_{1} x_{2} ; x_{1} x_{4} ; x_{1} x_{5} ; x_{2} x_{3} ; x_{2} x_{4} ; x_{2} x_{5}, x_{3} x_{5} ; x_{4} x_{5}, x_{1} x_{2} x_{3}, x_{1} x_{2} x_{4}, x_{1} x_{2} x_{5}, x_{1} x_{3} x_{5}, x_{1} x_{4} x_{5}$, $x_{2} x_{3} x_{4} ; x_{2} x_{3} x_{5} ; x_{2} x_{4} x_{5} ; x_{3} x_{4} x_{5} ; x_{1} x_{2} x_{3} x_{4} ; x_{2} x_{3} x_{4} x_{5}, x_{1} x_{2} x_{3} x_{4} x_{5}$. The rest of the factors are not significant. 
To determine the optimal parameters of the factors, we solve the optimization problem. Finding the parameter values at which the condition $\delta \rightarrow \min$ is achieved, is carried out with the introduction of the constraint $-1<x_{i}<+1$ [7-10].

As a result of solving this problem, the following optimal parameters of the acting factors were obtained (Table 2).

Table 2

Optimal values of the design and operating parameters of the vibratory sowing device

\begin{tabular}{|l|c|c|}
\hline \multicolumn{1}{|c|}{ Factor name } & Factor designation & Quantity \\
\hline Oscillation frequency, $\mathrm{s}^{-1}$ & $x_{1}$ & $5-7$ \\
\hline Vibration amplitude, $\mathrm{m}$ & $x_{2}$ & $0.02-0.04$ \\
\hline Angle of the chute to the horizon, degree & $x_{3}$ & $6-8$ \\
\hline Angular brush speed, $\mathrm{s}^{-2}$ & $x_{4}$ & $1-3$ \\
\hline Seeder travel speed, $\mathrm{km} \cdot \mathrm{h}^{-1}$ & $x_{5}$ & $8-10$ \\
\hline Brush diameter, $\mathrm{m}$ & $x_{6}$ & $0.06-0.08$ \\
\hline Chute width, $\mathrm{m}$ & $x_{7}$ & $0.04-0.05$ \\
\hline Clearance between the brush and chute, $\mathrm{m}$ & $x_{8}$ & $0.01-0.03$ \\
\hline
\end{tabular}

Visualization of the influence of various design parameters of the vibratory sowing device on the uneven seeding is provided using three-dimensional sections of the response surface. For greater clarity, the pattern of response changes and the possibility of predicting their values, the response surfaces are extrapolated outside the experimental area (Fig. 3).

a)

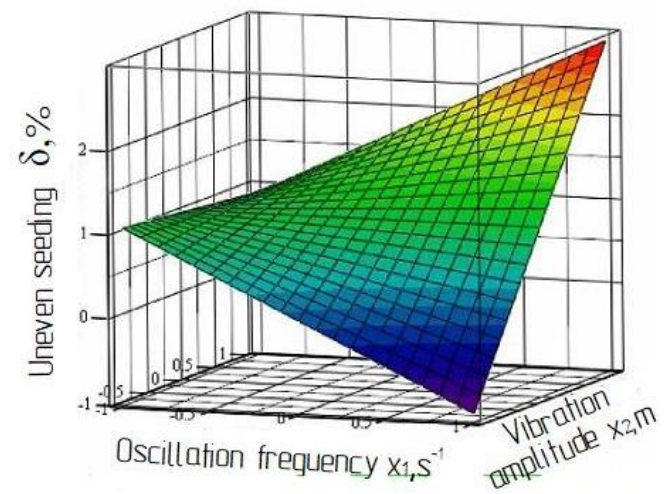

b)

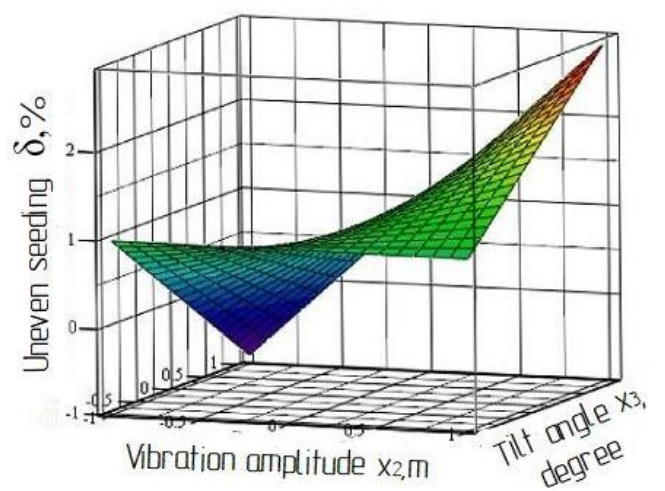

c)

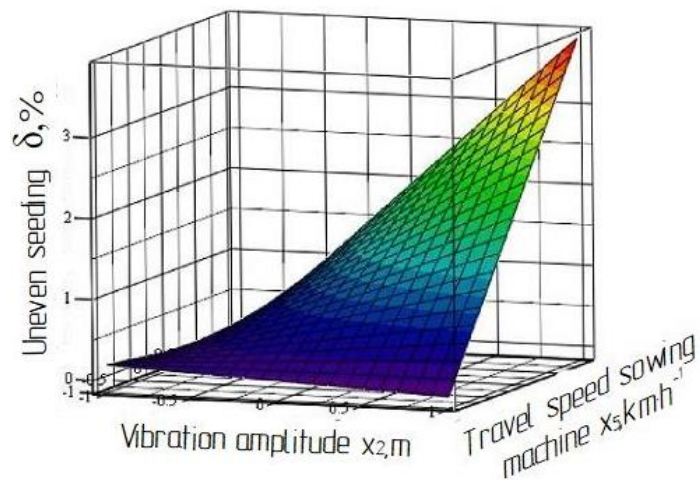

Fig. 3. Dependences of uneven seeding of seeds on frequency and the amplitude of oscillations (a) of uneven seeding of seeds on the amplitude fluctuations and the angle of inclination of the trough to the horizon (b) uneven seeding of seeds on the amplitude of vibrations and the speed of the seeder $(c)$

\section{Conclusions}

1. An increase in the oscillation frequency of the chute with a decrease in the amplitude leads to a decrease in uneven seeding; when the seeder moves at higher speeds and a greater amplitude of oscillations, an increase in the uneven seeding will be observed. 
2. High uniformity of seed dosage is achieved, when the angle of internal friction is $23^{\circ}-25^{\circ}$, and the angle of inclination is $26^{\circ}-30^{\circ}$.

3. The possibility of using a vibrating sowing device of the proposed design, when sowing winter wheat seeds with an irregularity of dosage within the permissible agrotechnical limits $\leq 3 \%$, has been experimentally confirmed. This is a decisive advantage of this device over a wheel-type metering device, which does not provide the required uniformity of metering.

4. The following optimal values of the design-mode parameters of the vibratory sowing device have been established: vibration frequency $-6 \mathrm{~s}^{-1}$; vibration amplitude $-0.03 \mathrm{~m}$; tilt angle -7 degree; angular speed of the brush $-2 \mathrm{~s}^{-1}$; seeder travel speed $-9 \mathrm{~km} \cdot \mathrm{h}^{-1}$; brush diameter $-0.07 \mathrm{~m}$; gutter width $-0.05 \mathrm{~m}$; gap between the brush and chute $-0.02 \mathrm{~m}$.

\section{References}

[1] Булавин С.А., Любин В.Н., Рыжков А.В., Мачкарин А.В., Быков Д.В. Сельскохозяйственная техника Белогорья (Agricultural machinery of Belogorye). Agricultural machinery and technology, No 1, 2010, pp. 39-41. (In Russian).

[2] Kolesnikov A., Pastukhov A., Vodolazskaya N., Minasyan A. Research in parameters of working process of interfusing in batcher mixer. Engineering for rural development. Jelgava: Latvia University of Life Sciences and Technologies, vol. 18, 2019, pp. 487-492.

[3] Romanenko E. Yu., Vodolazskaya N. V. Engineering in modern construction. IOP Conference Series: Materials Science and Engineering, 1083 (1), 2021, pp. 012055.

[4] Ivashina A., Adoshev F., Zhdanov V., Shemyakin V. Studying the electrical characteristics of grain under vibration action. Engineering for Rural Development. Jelgava: Latvia University of Life Sciences and Technologies, vol. 18, 2019, pp. 613-618.

[5] Булавин С.А., Мачкарин А.В., Рыжков А.В. Результаты испытаний сеялки прямого посева (Test results of the direct seeding drill) Bulletin of the Michurinsk State Agrarian University, No 1, 2015, pp. 119-125. (In Russian).

[6] Ivashina A., Adoshev A., Antonov S., Logacheva E. Method for measuring moisture of grain mass under vibration. Engineering for Rural Development. Jelgava: Latvia University of Life Sciences and Technologies, vol. 19, 2020, pp. 1121-1127.

[7] Vodolazskaya N. Types and ways of modernization in a context of the international experience. Virtual Economics, Vol.2. No 2(1), 2019, pp. 81-93.

[8] Мачкарин А.В., Рыжков А.В. Теоретические исследования вибросмешивания сыпучих кормов (Theoretical studies of vibration mixing of bulk feed). Innovations in agrarian and industrial complex: problems and prospects, No 3 (23), 2019, pp. 43-55. (In Russian).

[9] Khafizov R., Khafizov C., Nurmiev A., Galiev I. Optimization of main parameters of tractor and unit for seeding cereal crops with regards to their impact on crop productivity. Engineering for Rural Development. Jelgava, 2018, pp. 168-175.

[10] Azadi M.S., Younesi E. The effects of storage on germination characteristics and enzyme activity of sorghum seeds. Journal of Stress Physiology \& Biochemistry, Vol. 9(4), 2013, pp.289-298.

[11] Scarlett A. J. Integrated control of agricultural tractors and implements: review of potential opportunities relating to cultivation and crop establishment. Computers and Electronics in Agriculture, 30: 2001, pp. 167-191.

[12] Vodolazskaya N., Sharaya O. Modifying of the Surface of Products from Cast Iron as the Element of Production Modernization. Solid State Phenomena, vol. 299, 2020, pp. 588-593.

[13] Smith D.R. Pulsation, vibration, and noise issues with wet and dry screw compressors. Proceedings of the 41st Turbomachinery Symposium, September 24-27, 2012, Houston, Texas, pp. 1-33.

[14] Rao S.S. Mechanical vibrations. Second edit. Addison-Wesley Publishing Company, 1990. 716p.

[15] Liang X.et al. Vibration Signal Modeling for a Planetary Gear Set. Engineering Failure Analysis, vol. 48, 2015, pp. 185-200. 